УДК 621.43

\title{
ЧИСЛЕННОЕ МОДЕЛИРОВАНИЕ ПРОЦЕССОВ ТЕПЛО- И МАССООБМЕНА В БОРТОВОМ КАВИТАТОРЕ СИСТЕМЫ ПОДДЕРЖАНИЯ СТАБИЛЬНОСТИ АВТОМОБИЛЬНЫХ СМЕСЕВЫХ ТОПЛИВ
}

\author{
Левтеров А.М., к.т.н., Авраменко А.Н., к.т.н., Мараховский В.П., Бганцев В.Н., к.т.н. \\ Институт проблем машиностроения им. А.Н. Подгорного НАН Украины, \\ ул. Пожарского, 2/10, Харьков, Харьковская область, Украина, 61000
}

В роботі розглядаються особливості математичного моделювання процесу гідродинамічної кавітації автомобільного сумішевого палива - бензоетанолу. В математичній моделі процесу гідродинамічної кавітації враховуються процеси фазових переходів рідина - пара рідина, з урахуванням процесу течії неоднорідного двофазного потоку (модель суміші).

Библ. 7 , рис. 3 .
В работе рассматриваются особенности математического моделирования процесса гидродинамической кавитации автомобильного смесевого топлива - бензоэтанола. В математической модели процесса гидродинамической кавитации учитываются процессы фазовых переходов жидкость - пар - жидкость, с учетом процесса течения неоднородного двухфазного потока (модель смеси).
In work features of mathematical modelling of process hydrodynamical cavitation automobile blend fuel gazolin-alcohol are considered. In mathematical model process hydrodynamical cavitation processes of phase transitions a liquid - pairs - a liquid are taken into account, in view of process of current of a non-uniform biphase stream (mix model).

Ключевые слова: гидродинамическая кавитация, число кавитации, двигатель, бензоэтанол, двухфазный поток.

ДВС - двигатель внутреннего сгорания;

$X$ - число кавитации;

$P$ - гидростатическое давление набегающего потока;

$P_{н n}$ - давление насыщенных паров жидкости при

определенной температуре окружающей среды;

\section{введение}

Стремление снизить зависимость автомобилей от нефтепродуктов и ужесточение норм к токсичности отработавших газов ДВС приводит к необходимости использования альтернативных видов топлив. Одними из перспективных альтернативных топлив для двигателей с искровым зажиганием являются бензоспиртовые смеси (бензоэтанол). Использование бензоэтанола широко распространено в США и странах Южной Америки, особенно в Бразилии [1]. В этих странах преобладает относительно теплый климат и, соответственно, приемлемые условия для использования бензоэтанола, однако в северных штатах США бензоэтанол продают преиму-
$V$ - скорость потока на входе в систему;

$\rho$ - плотность среды;

k-e - название модели турбулентности;

\section{Индексы:}

нn - насыщенные пары.

щественно в теплое время года [2].

Одним из проблемных вопросов использования бензоэтанола в ДВС с искровым зажиганием является более низкое давление насыщенных паров, и соответственно, затрудненный запуск двигателя в условиях низких температур и возможность расслоения бензоэтанола в топливном баке автомобиля в случае попадания воды в топливо из атмосферного воздуха (гигроскопический эффект обусловленный наличием этанола) или эксплуатацией при пониженных температурах воздуха - в случае недостаточного воздействия стабилизирующих присадок к бензоэтанолу $[2,3]$.

Таким образом, проблема поддержания ста- 
бильности смесевых топлив, в первую очередь бензоэтанола, на борту транспортного средства является актуальной.

\section{Анализ публикаций}

В установках для приготовления смесевых топлив в промышленных масштабах, как правило используется эффект гидродинамической кавитации [4], так как ультразвуковая кавитация считается более энергозатратной по сравнению с гидродинамической [4]. При этом производители декларируют стабильность, к примеру, бензоспиртовых смесей в течение трех месяцев с момента производства при соблюдении условий хранения смесевого топлива [4].

В последнее время появились новые технологии приготовления бензоэтанола из бензина и абсолютизированного спирта. Такой метод не требует специальных смешивающих устройств типа кавитаторов, а позволяет ограничиться только перемешиванием компонент топлива в процессе приготовления композиции.

При эксплуатации двигателей, работающих на бензоэтаноле, приготовленном из бензина и абсолютизированного спирта, возникают проблемы, связанные с гигроскопичностью спирта и негерметичностью топливной системы автомобиля. Структура автопарка Украины представлена преимущественно автомобилями прошлых поколений, у которых у силу различных причин топливный бак сообщается с атмосферой, что вызывает неизбежное абсорбирование воды из атмосферного воздуха. Это в свою очередь, неизбежно приводит к последующему расслоению смесевого топлива в топливном баке и проблемам в эксплуатации (затруднен или невозможен запуск двигателя и ухудшение энергоэкологических показателей ДВС).

Для поддержания стабильности смесевого топлива и обеспечения эффективной работы ДВС на бензоэтаноле на борту автомобиля могут использоваться малогабаритные гидродинамические кавитаторы. Основными требованиями к таким устройствам являются - эффективность обработки топлива, минимальные массогабаритные показатели и минимальные энергозатраты на работу системы.

Большинство конструкций бортовых кавитаторов представленных на рынке не удовлетворя- ют этим требованиям по одному или нескольким параметрам. Так, например, авторы [5] декларируют для гидродинамического кавитатора своей конструкции определяющий параметр - число кавитации $(\mathrm{X}), \mathrm{X}>1$. По известной формуле

$X=\frac{2 \cdot\left(P-P_{н n}\right)}{V^{2} \cdot \rho}$,

где $P$ - гидростатическое давление набегающего потока, Па; $P_{\text {нn }}$ - давление насыщенных паров жидкости при определенной температуре окружающей среды, Па; $V$ - скорость потока на входе в систему, м/с; $\rho$ - плотность среды, кг/ $\mathrm{M}^{3}$;

Значения $\mathrm{X}>1$ противоречит условиям возникновения кавитации в потоке [6] и это вызывает сомнения в задекларированной экономии штатного топлива (бензина) на уровне $15 . .30 \%$ при использовании на авто с современными системами управления ДВС [5].

С учетом отмеченного, разработка системы поддержания стабильности смесевых топлив на борту автомобиля, с использованием гидродинамических кавитаторов является важной задачей для автомобильной транспортной сферы Украины.

Цель работы - оценка параметров работы бортового гидродинамического кавитатора системы поддержания стабильности бензоспиртовых топлив с использованием численных методов.

\section{Задачи:}

- провести литературный обзор по методам математического моделирования процесса гидродинамической кавитации смесевых автомобильных топлив;

- сформулировать требования к конструкции и условиям работы бортового гидродинамического кавитатора;

- сформировать массив краевых условий для расчета;

- синтезировать расчетную область и дискретную сетку, представляющую конфигурацию проточной части бортового гидродинамического кавитатора;

- смоделировать работу бортового гидродинамического кавитатора на расчетном режиме;

- проанализировать результаты расчетного исследования; сделать выводы и сформулировать рекомендации о перспективах использования 
малогабаритных гидродинамических кавитаторов для поддержания стабильности бензоспиртовых смесей на борту автомобиля.

Основные этапы и результаты сводятся к следующему. На основе данных литературного обзора и с учетом требований к массогабаритным показателям и гидравлическим характеристикам бортового гидродинамического кавитатора были разработаны варианты его конструктивного исполнения. На конструкцию, рассматриваемого в статье бортового гидродинамического кавитатора, авторами был получен патент Украины [7].

При выборе основных конструктивных размеров использовались известные аналитические зависимости, позволяющие предварительно оценить условия возникновения кавитации в гидродинамическом устройстве. Число кавитации (X) для рассматриваемого конструктивного варианта на расчетном режиме менее 0,75 , что свидетельствует о возможности реализации интенсивной кавитации топлива в диффузоре гидродинамического кавитатора [6]. Углы раскрытия конусов конфузора и диффузора выбирались на основе требований к массогабаритным показателям бортового гидродинамического кавитатора, условий зарождения, роста, течения и схлопывания кавитационных каверн в потоке и ресурсных показателей кавитатора.

Параметры цилиндрического канала, соединяющего конфузор и диффузор гидродинамического кавитатора, для последующего численного моделирования выбирались с учетом расходных характеристик штатных топливных насосов, устанавливаемых на большинство автомобилей, представленных автопарком Украины системы поддержания стабильности смесевого топлива на борту автомобиля, а также минимальных энергозатрат на функционирование.

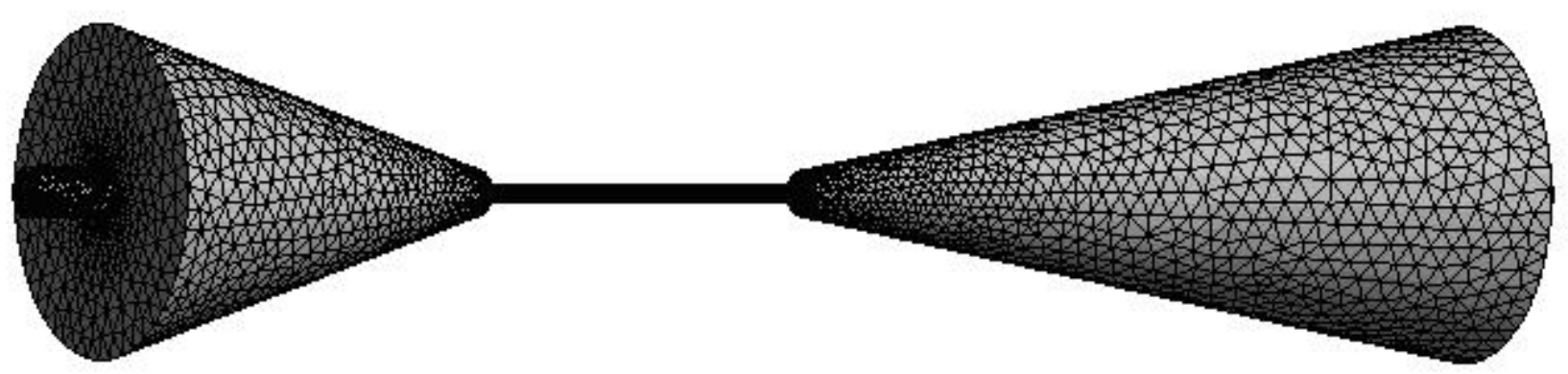

Рис. 1. Дискретная сетка (3230054 расчетных ячеек).

С использованием численных методов, был смоделирован процесс течения топлива (бензоэтанола) в проточной части гидродинамического кавитатора системы поддержания стабильности смесевого топлива на борту автомобиля. Задача решалась в нестационарной трехмерной постановке, в декартовых координатах. Для описания турбулентных течений топлива в проточной части использовались k-е модель турбулентности.

Для описания процесса гидродинамической кавитации использовалась модель многофазных течений. При этом, учитывая ограничения используемой модели (модель не позволяет описывать процесс фазового перехода двух компонент одновременно - спирта и бензина), в работе рассматривается топливная композиция с усредненными теплофизическими параметра- ми (бензоэтанол Е40 - 40 \% спирта). Поэтому, база данных программного комплекса была дополнена свойствами нового рабочего тела бензоэтанола Е40. Для описания процесса течения двухфазного потока (пар и жидкость) в работе использовалась модель смеси (Mixture model).

Также в расчете учитывалась шероховатость стенок проточной части гидродинамического кавитатора и теплообмен между стенками и рабочим телом (бензоэтанолом).

Результаты расчетного исследования представлены на рис. 2 и 3.

Пример распределения давления топлива в меридиональном сечении проточной части гидродинамического кавитатора представлен на рис. 2, $a$. В конфузоре на расчетном режиме давление потока бензоэтанола достигает 
0,115 МПа. В соединительном канале между конфузором и диффузором поток набирает скорость и давление в нем снижается до уровня, ниже атмосферного - 0,035 МПа. На входе в диффузор скорость потока остается достаточно высокой и, соответственно, давление сохраняется ниже атмосферного - 0,092 МПа, что существенно ниже давления насыщенных паров бензоэтанола.

Распределение полной скорости по раз-
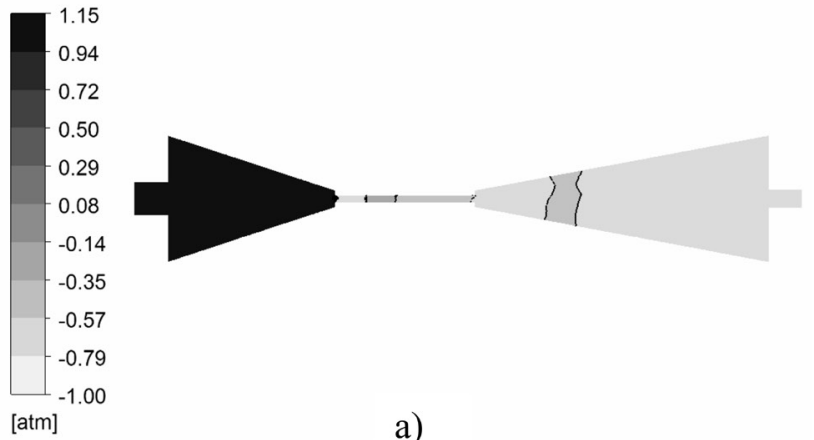

a)
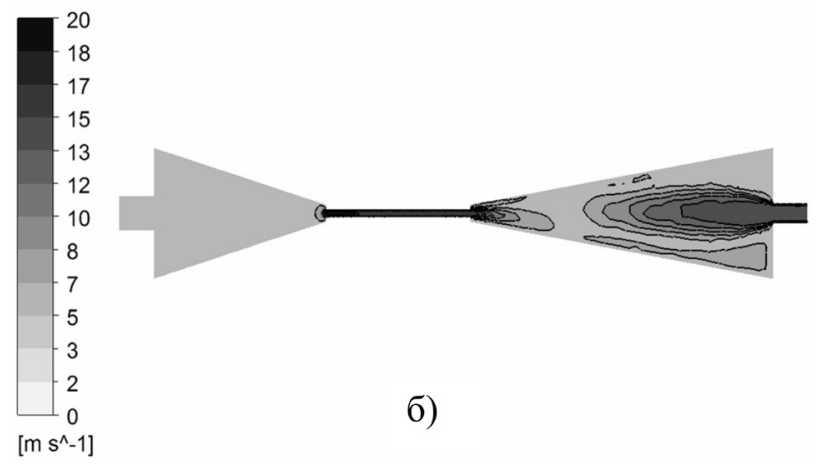

б)
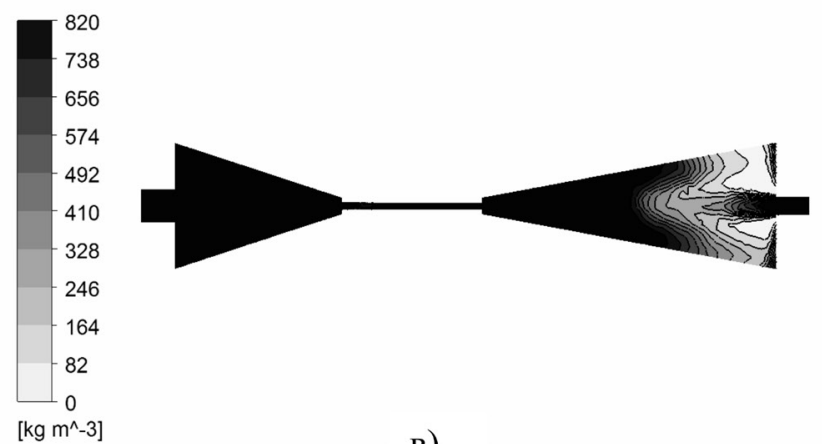

$\left[\mathrm{kg} \mathrm{m}^{\wedge}-3\right]$

в)
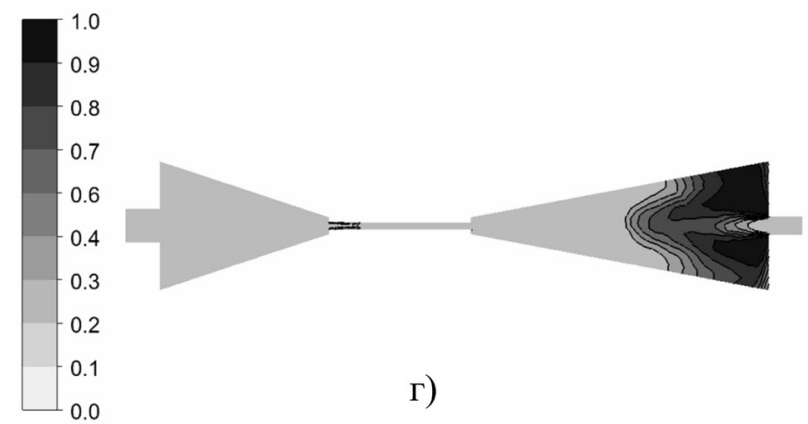

Рис. 2. Распределение давления (а), скорости (б), плотности (в) и объемной доли паровой фазы (2) в проточной части гидродинамического кавитатора. 
личным участкам потока топлива в меридиональном сечении проточной части гидродинамического кавиатора представлен на рис. 2, б. На входе в конфузор полная скорость потока топлива достигает 1,3 м/с. При движении через соединительный канал между конфузором и диффузором поток набирает скорость до 20 м/с, при этом уже в соединительном канале наблюдается зарождение кавитационных каверн из-за резкого падения давления. На выходе из диффузора полная скорость потока сохраняется достаточно высокой и имеет значение $14 \mathrm{~m} / \mathrm{c}$.

Распределение плотности рабочего тела (смеси жидкости и паров бензоэтанола) в меридиональном сечении проточной части гидродинамического кавиатора представлен на рис. 2, в. Наибольшее снижение плотности отме- чается на участках с пониженным давлением - в области зарождения кавитационных каверн.

Распределения объемной доли паровой фазы бензоэтанола в меридиональном сечении проточной части гидродинамического кавиатора представлен на рис. 2, г. Наибольшее количество паровой фазы отмечается в пристеночной области выходного отверстия диффузора.

Осредненное по объему изменение сходимости объемной доли паровой фазы бензоэтанола в проточной части гидродинамического кавитатора в процессе расчета представлено на рис. 3. Из рисунка 3 видно, что стабилизация сходимости объемной доли паровой фазы бензоэтанола в процессе расчета достигается при 4000 итераций, при этом значение объемной доли паровой фазы бензоэтанола составляет 0,325 .

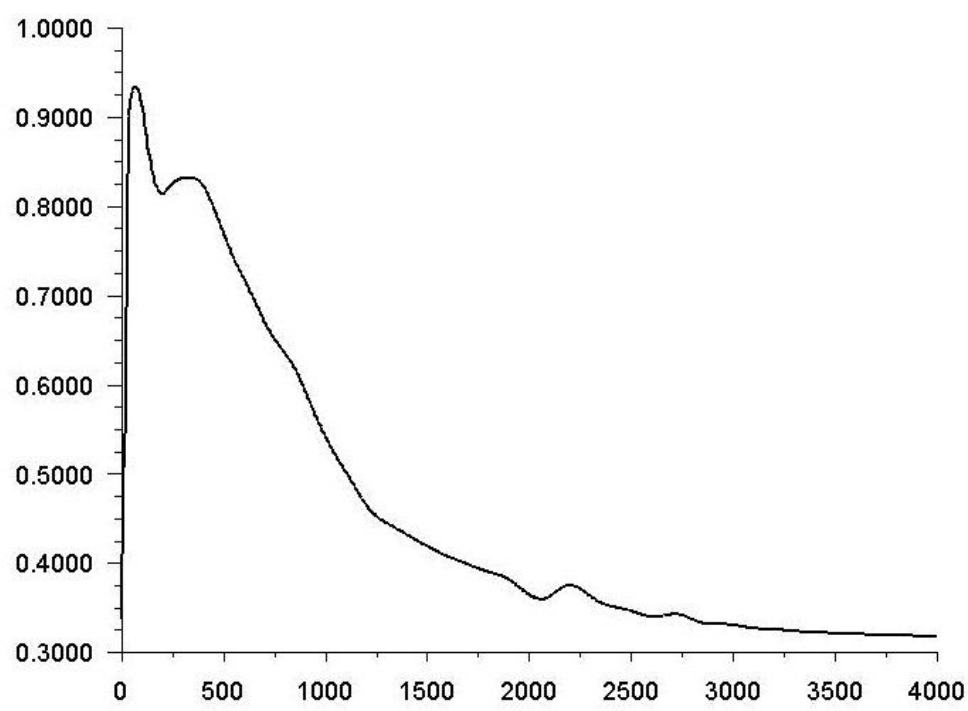

Рис. 3. Изменение сходимости объемной доли паровой фазы бензоэтанола в проточной части гидродинамического кавитатора в зависимости от количества итераций.

Таким образом, на расчетном режиме при движении бензоэтанола через гидродинамический кавитатор, за один проход только порядка $30 \%$ топлива подвергается фазовому переходу, а большая часть топлива проскальзывает в пристеночном слое за счет вязкого трения жидкости о стенки проточной части кавитатора и инерционности потока.

Существенного увеличения интенсивности обработки (объемной доли паровой фазы бензоэтанола) можно достигнуть за счет уменьше- ния диаметра соединительного канала между конфузором и диффузором или за счет последовательной установки в топливную систему нескольких гидродинамических кавитаторов, что неизбежно приведет к росту энергозатрат на работу системы поддержания стабильности смесевого топлива на борту автомобиля и увеличению массогабаритных показателей устройства.

Стремление уменьшить диаметр соединительного канала так же обладает рядом 
дополнительных ограничений - в процессе эксплуатации соединительный канал может забиваться продуктами износа или присадками к топливу, что может привести к потере мощности или аварийной остановке двигателя.

Как известно, процесс гидродинамической кавитации сопровождается эрозионным износом стенок проточных частей гидродинамических устройств.

Из результатов, представленных на рис. 3 6 видно, что конструкция проточной части бортового гидродинамического кавитатора, на расчетном режиме, позволяет реализовать процесс гидродинамической кавитации смесевого топлива (бензоэтанола) в потоке - без непосредственного контакта кавитационных каверн при экстремальных термодинамических параметрах со стенками проточной части диффузора.

Таким образом, процесс гидродинамической кавитации реализован в потоке, и лишь достигнув стенок, ограничивающих выходное отверстие диффузора каверны могут контактировать со стенками, но уже при менее экстремальных термодинамических параметрах. За счет этой особенности в последующих работах, при проведении экспериментальных исследований, можно рассчитывать на достаточный ресурс рассматриваемого бортового гидродинамического кавитатора, что особенно важно для перспектив его использования на автомобильном транспорте.

По результатам проведенного расчетного исследования можно сделать выводы:

- применение компактных бортовых гидродинамических кавитаторов в системе питания ДВС транспортного средства позволит поддерживать стабильность бензоэтанола и тем самым повысить эффективность использования этого вида топлива;
- предложенная в работе конфигурация проточной части гидродинамического кавитатора позволяет на борту транспортного средства поддерживать стабильность бензоэтанола, и при этом обеспечить необходимый ресурс кавитатоpa.

\section{ЛІТЕРАТУРА}

1. Александров A.A. Альтернативные топлива для двигателей внутреннего сгорания: монография / А.А. Александров,И.А. Архаров, В.В. Багров и др. - М.: ООО НИЦ «Инженер», 2012. $790 \mathrm{c.}$

2. Fuel Economy of 2013 Flex-Fuel (E85) Vehicles [Електронний ресурс]/U.S. Department of Energy. - 2012. - Режим доступа: http://www.fueleconomy. gov/feg/byfuel/ FFV2013.html.

3. ADAPTER E85 [Електронний ресурс]/GREENBUTTON ECOTECHNICS. - 2011. - Режим доступа: http:/greenbutton.org/ru/adapter-85.html

4. Производство высококачественного товарного смесевого бензина из дешевых компонентов. Гомогенизация бензинов. - 2007. - Режим доступа: http:/www.ukrbudmash.com.ua/ru/fuel_ blending_system.htm

5. Топливный кавитатор - экономия топлива. 2014. - Режим доступа: http://www.afuelsystems. com/ru/cavitator.html

6. Иванов А. Н. Гидродинамика развитых кавитационных течений, Л., 1980.

7. Пат. 97284, Украина, МПК F02M 27/08 (2006.01), F02M 27/04 (2006.01) Топливный кавитатор / Левтеров, А. М., Авраменко, А. Н., Мараховский, В. П., Бганцев, В. Н. - Заявитель и патентодержатель "Институт проблем машиностроения им. А.Н. подгорного” НАН Украины. - № u 2014 09044. - Заяв. 11.08.2014. Опубл. 10.03.2015. Бюл. № 5. 
NUMERICAL MODELLING OF PROCESSES WARMLY - AND MASS TRANSFER IN ONBOARD CAVITATION SYSTEMS OF MAINTENANCE OF STABILITY AUTOMOBILE FUEL BLEND

\section{Levterov A., Avramenko A., Marahovskiy V., Bgancev V.}

Institute for Machine Building Problems named after A.N. Podgorny of National Academy of Sciences of Ukraine

2/10 Pozharsky St., Kharkiv, 61046, Ukraine

The article describes the main stages and results of mathematical modeling of heat and mass transfer in fluid cavitator. In mathematical modeling in describing the cavitation processes in the body is seen as a working gasoline and blend fuel - gazolinalcohol. The estimation of operating parameters board hydrodynamic cavitator maintain system stability benzospirtovyh fuels using numerical methods. It was found that the use of compact board hydrodynamic cavitators in the fuel system of the internal combustion engine the vehicle will maintain benzoetanola stability and thereby increase the efficiency of this type of fuel.

Key words: hydrodynamic cavitation, the cavitation number, engine benzoetanol, two-phase flow.
1. Aleksandrov A.A. Alternative fuel for internal combustion engines: monophy / A.A. Alexandrov, I.A. Arkharov, VV BaGrove and others -. M .: OOO SIC "Engineer", 2012. -790.(Rus.)

2. Fuel Economy of 2013 Flex-Fuel (E85) Vehicles [Electron resource]/U.S. Department of Energy.2012. - Access: http: //www.fueleconomy.gov / feg / byfuel / FFV2013.html.

3. ADAPTER E85 [Electron resource] / GREENBUTTON ECOTECHNICS. - 2011. - mode preStupa: http://greenbutton.org/ru/adapter-85.html

4. Manufacture of high quality goodstion mix gasoline cheap components. Homogenization gasoline. 2007 - Mode. Access: http://www.ukrbudmash.com. ua/ru/fuel_blending_system.htm. (Rus.)

5. Fuel cavitator - fuel economy. - 2014. - Access: http: //www.afuelsystems.com / ru / cavitator.html. (Rus.)

6. Ivanov A.N. Hydrodynamics developed cavitatational movements , L. , 1980 .(Rus.)

7. Pat . 97284, Ukraine, IPC F02M 27/08 (2006.01), F 02M 27/04 (2006.01) Fuel chamber vitator / Levterov , AM , Avramenko , AN ,Marakhovskii , $\mathrm{VP}$, Bgancev , VN - Applicant and patent holder " Institute of machine problems eneering them . AN Podgorny " National Academy of Sciences of Ukraine. - No u 2014 09044. - said. 08/11/2014 . Publ .03/10/2015 . Bull. No 5 .(Rus.) 